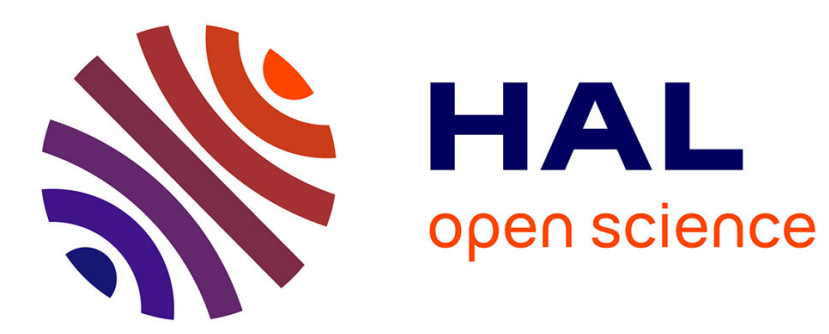

\title{
Damage accumulation studies in ion-irradiated oxides: Current status and new perspectives
}

\author{
Jacek Jagielski, Lionel Thomé, Alain Chartier, Orest Dorosh, Cyprian \\ Mieszczynski, Iwona Jozwik
}

\section{- To cite this version:}

Jacek Jagielski, Lionel Thomé, Alain Chartier, Orest Dorosh, Cyprian Mieszczynski, et al.. Damage accumulation studies in ion-irradiated oxides: Current status and new perspectives. Nuclear Instruments and Methods in Physics Research Section B: Beam Interactions with Materials and Atoms, 2018, 435, pp.2-7. 10.1016/j.nimb.2017.11.015 . cea-02428754

\section{HAL Id: cea-02428754 https://hal-cea.archives-ouvertes.fr/cea-02428754}

Submitted on 6 Jan 2020

HAL is a multi-disciplinary open access archive for the deposit and dissemination of scientific research documents, whether they are published or not. The documents may come from teaching and research institutions in France or abroad, or from public or private research centers.
L'archive ouverte pluridisciplinaire HAL, est destinée au dépôt et à la diffusion de documents scientifiques de niveau recherche, publiés ou non, émanant des établissements d'enseignement et de recherche français ou étrangers, des laboratoires publics ou privés. 


\title{
Damage accumulation studies in ion-irradiated oxides: Current status and new perspectives
}

\author{
Jacek Jagielski $^{\mathrm{a}, \mathrm{b}, *}$, Lionel Thomé ${ }^{\mathrm{c}}$, Alain Chartier ${ }^{\mathrm{d}}$, Orest Dorosh ${ }^{\mathrm{b}}$, Cyprian Mieszczynski $^{\mathrm{b}}$, \\ Iwona Jozwik ${ }^{\mathrm{a}}$ \\ a Institute of Electronic Materials Technology, Wolczynska 133, 01-919 Warsaw, Poland \\ ${ }^{b}$ National Centre for Nuclear Research, A. Soltana 7, 05-400 Otwock/Swierk, Poland \\ ${ }^{\mathrm{c}}$ Centre de Sciences Nucléaires et de Sciences de la Matière, Université Paris-Saclay, Bât 108, 91405 Orsay Campus, France \\ ${ }^{\mathrm{d}}$ DEN-Service de la Corrosion et du Comportement des Matériaux dans leur Environnement (SCCME), CEA, Université Paris-Saclay, 91191 Gif-sur-Yvette, France
}

\section{A R T I C L E I N F O}

\section{Keywords:}

Oxides

Ion irradiation

Damage accumulation

Radiation defects

\begin{abstract}
A B S T R A C T
The main purpose of this paper is to summarize our results obtained during research on the radiation behavior of oxides. The paper presents various methods of damage accumulation in irradiated oxides with the special emphasis on correlations between channeling, luminescence and Raman spectroscopy measurements as well as the possibility to obtain quantitative data on polycrystalline materials. The results are interpreted in terms of Multi Step Damage Accumulation model. Without pretending to give a full review of the current trends concerning these studies, we intend to present both a reflection about recent results and a few options for next investigations. This article can thus be regarded as the opening of a discussion on further directions of the research to be conducted on the topic of radiation damage formation in advanced materials for nuclear applications.
\end{abstract}

\section{Introduction}

The investigation of the damage accumulation process in irradiated solids is one of the key issues of nuclear engineering. This topic is thus intensively studied since the beginning of the nuclear technology era (few examples of review papers can be found in Refs. [1-10]. The development of predictive models for the behavior of materials in nuclear installations requires detailed understanding of the mechanisms leading to structural transformations to create a basis for understanding their functional properties. In general the study of the damage accumulation process involves three main aspects: (i) the identification of the type of defects that are created at the various stages of the damaging process, (ii) the quantitative determination of the damage level and (iii) the modelling of the damage accumulation buildup. Various experimental and simulation tools may be used to achieve the goals listed above. The most reliable technique for the determination of the defect structure is certainly transmission electron microscopy (TEM), whereas the quantitative analysis of the damage and stress levels is generally done using Rutherford backscattering/channeling (RBS/C) and Xray diffraction (XRD) [11]. The current status of the results collected for ion-irradiated oxides will be reviewed in the first part of the paper.
Numerous studies performed in the past allowed to collect a solid database to describe the evolution of defects upon irradiation and to build models (mainly phenomenological) of damage accumulation. In our paper we are using Multi Step Damage Accumulation model described in Ref. [12].

A critical review of the available information points to missing elements in damage accumulation studies. Among them, the need to: (i) find a technique providing a quantitative assessment of the damage level in polycrystals, and (ii) close a gap between atomistic simulations (essentially made by using Molecular Dynamics - MD, sometimes combined with Kinetic Monte Carlo and Rate Equations Cluster Dynamics) and experimental results, appears as the most urgent tasks. Although some experimental validations of atomistic simulations have been made already (e.g. see the study of $\mathrm{ZrC}$ [13]) this topic is still far from being solved. These topics are addressed in the second part of the paper, together with preliminary results of attempts made to fill these needs using luminescence techniques and a new approach for MD.

The last part presents a proposition, what can be done for a better understanding of the damage accumulation process in irradiated oxides, a description of the approach that combines advanced experimental techniques (RBS/C, TEM, XRD), MD simulations and phenomenological modelling.

\footnotetext{
* Corresponding author at: Institute of Electronic Materials Technology, Wolczynska 133, 01-919 Warsaw, Poland.

E-mail address: jacek.jagielski@itme.edu.pl (J. Jagielski).
} 


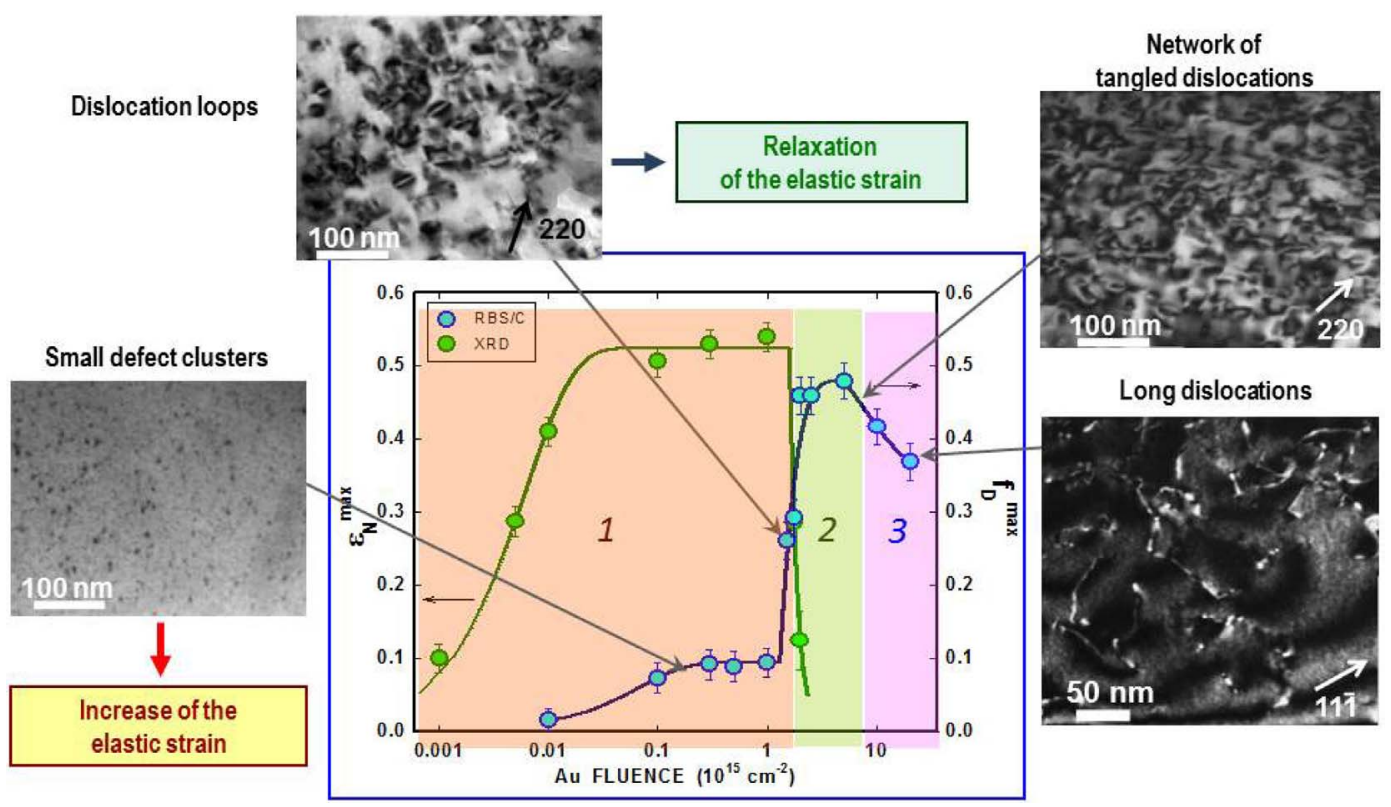

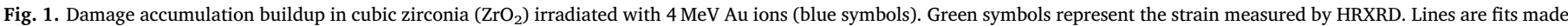

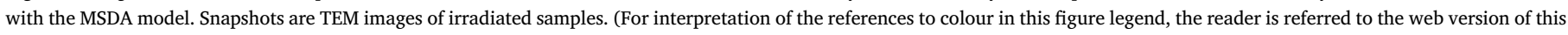
article.)

\section{Current status of research on damage accumulation in ion- irradiated oxides}

Numerous experimental studies were devoted to the investigation of the structural transformations induced by elastic collisions in oxides submitted to low-energy ion irradiation. In these experiments the quantitative measurement of the damage and strain levels in ion-irradiated single crystals was generally made by using the RBS/C and XRD techniques. In addition, transmission electron microscopy (TEM) observations allowed the identification of the defects created at the various stages of the damage buildup. A typical example summarizing the collected data is shown in Fig. 1 for cubic zirconia irradiated with medium-energy heavy ions [14]. The damage accumulation buildup can be divided into three distinct regions exhibiting: (i) a small defect cluster production leading to a fast increase of the strain at low fluences; (ii) a sudden release of the strain associated with a sharp increase of the damage level due to the formation of dislocation and dislocation loop at intermediate fluences; (iii) a growth of dislocations that may lead to the polygonization of the crystal structure at high fluences [15]. The damage accumulation process can be described by using the multistep damage accumulation (MSDA) model [12] (solid lines in Fig. 1), which relies on the assumption that the damage accumulation occurs in a series of steps, each step being characterized by a dominant type of defects. The type of defect which is associated to a given step is determined by the lowest free energy of this specific atomic configuration.

The sequence of structural transformations described above for ionirradiated zirconia is typical for most of oxides (and even other kinds of materials) irradiated in the elastic collision regime, i.e. with low- or medium-energy ions. The modification of the dominant defect configuration at each step of the damage process is triggered by external solicitations, such as stress formation or changes in the sample stoichiometry (when the implanted ion concentration reaches a sufficiently high level). The latter aspect is particularly important when very lowenergy ions are used that lead to the overlap of the damaged layer and of the region where ions are stopped inside the matrix. Thus, the effects observed are due to displacements of target atoms, but also to changes of the target composition by the incorporation of foreign elements.

A still unsolved problem that should be elucidated is the real structure of the defects which are formed at the different steps of the damage accumulation process. Relatively large defects were observed at high irradiation fluences that may be identified as dislocations or dislocation loops. The situation is less clear at low fluences where the size of radiation defects is very small (a few nanometers), hence difficult to identify by TEM. A recent study of defect formation in ion-irradiated ZnO [16] showed that near the surface small basal loops are preferentially formed, whereas in deeper regions prismatic loops are more likely created (Fig. 2). These results have been confirmed by Monte Carlo simulations made with the McChasy code [17] that allow the reproduction of RBS/C spectra for crystals containing dislocations [18], hence depth distributions of different types of defects in the crystal. Detailed in-situ experiments performed on electron- and ion-irradiated ceria and zirconia demonstrated that small dislocations are already formed at the early stages of the damage accumulation process $[19,20]$. Moreover, MD simulations made on irradiated $\mathrm{UO}_{2}$ crystals [21] support the hypothesis that small dislocation loops may be formed as a direct result of cascade collapse. The change in the orientation of dislocation loops with depth may be explained by the stress distribution: (i) in the vicinity of the sample surface the stress may be partially released through swelling, hence the basal orientation of dislocation loops is energetically favored; (ii) at deeper depths the compressive stress parallel to the surface leads to the formation of prismatic loops. It is worth pointing out that the change in the dislocation loop orientation with depth allows one to explain the results obtained by RBS/C, TEM, and MD. TEM and MD results predict that dislocation loops should be preferentially formed in irradiated $\mathrm{ZnO}$, whereas $\mathrm{RBS} / \mathrm{C}$ data suggest that near the surface interstitial atoms are mainly observed. Basal loops located in the near-surface region lead to a blocking of channels in the crystalline structure, hence to a backscattering process similar to that observed in the case of interstitial atoms. At higher depths prismatic loops cause defocalization of the analyzing beam in bent channels, leading to an increase of the backscattering yield in the low-energy part of the spectrum. The hypothesis that the defects leading to different contributions in the dechanneling yield (up to now described as Randomly Displaced Atoms (RDA) and Bent Channels (BC) in the McChasy code) are actually different forms of dislocations is a highly reasonable hypothesis. It leads to the conclusion that the type of defects formed during irradiation is essentially defined by the material. In other words, in amorphization resistant solids dislocations are always predominantly formed, the stress mainly leading to changes in their orientation and size. 

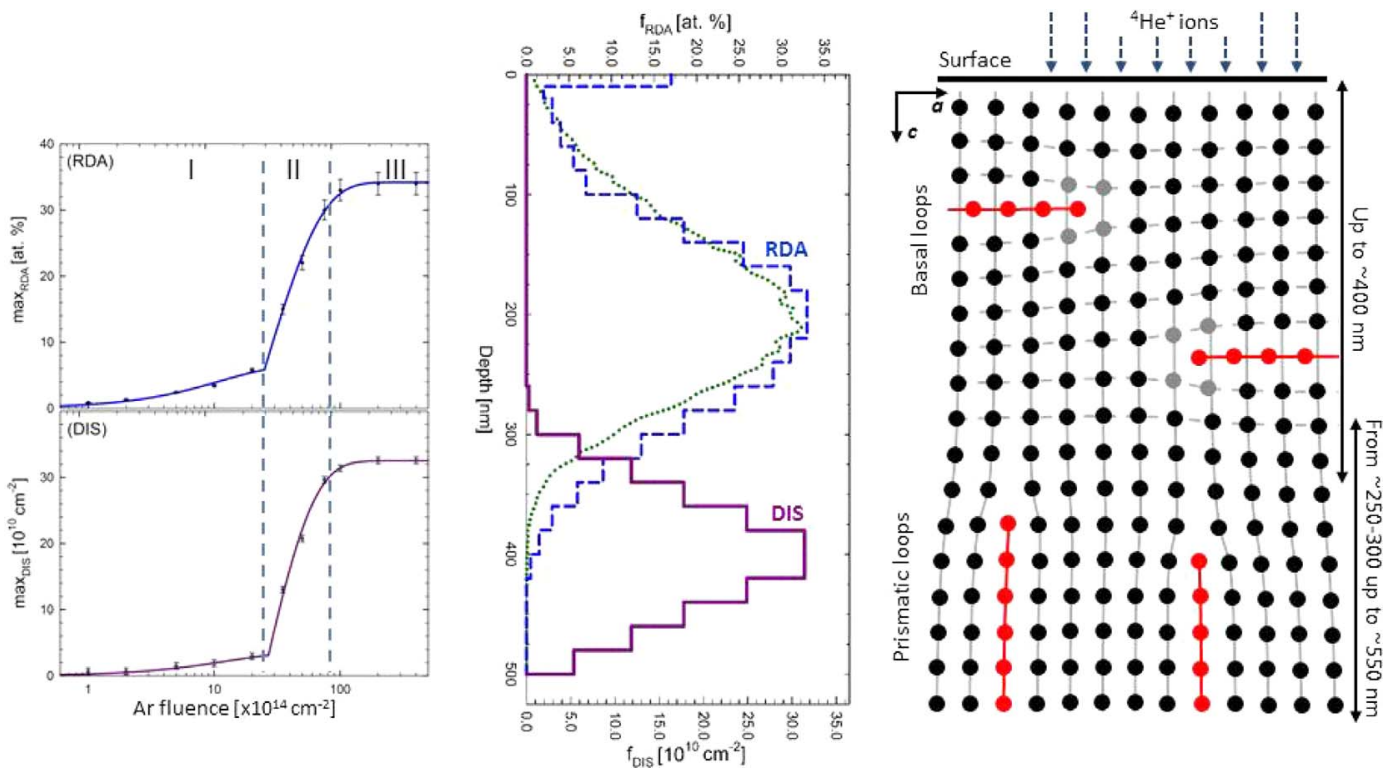

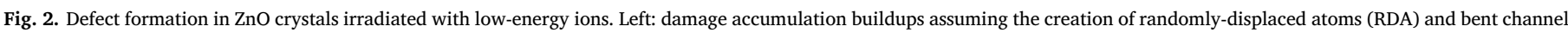
(DIS). Middle: depth distributions of RDA and DIS. Right: schematic representation of the structure of the defects created as a function of depth in the crystal.

\section{New achievements due to the use of advanced experimental techniques}

As it was discussed in the previous section, the determination of the damage accumulation in ion-irradiated crystals was mainly done by using the RBS/C technique [11]. However, one of the main drawbacks of this technique is its limitation to the analysis of single crystals. Taking into account that most of engineering constructions are made of polycrystalline materials, the need to find experiments able to measure the damage formation in polycrystalline solids is obvious. Several advanced techniques were tested for this purpose. Among them luminescence and Raman are certainly the most promising ones [22,23].

In luminescence experiments, the excitation may arise from different sources: light (photoluminescence - PL), electrons (cathodoluminescence - CL) or ions (ionoluminescence - IL). A significant advantage of IL is the possibility to adjust the range of ions used for excitation to the thickness of the damaged layer, hence to eliminate the signal coming from deeper undamaged parts of the material. An example of such experiments performed on mono- and polycrystalline $\mathrm{MgAl}_{2} \mathrm{O}_{4}$ samples irradiated with $320 \mathrm{keV}$ Ar ions is presented in [22]. In this work $\mathrm{a} \mathrm{H}_{2}$ ion beam with an energy of $86 \mathrm{keV}$ was used to excite the luminescence. The analyzing $\mathrm{H}_{2}$ beam energy and angle of incidence, i.e. the penetration depth and sampling volume, was selected to fit the depth of damage created during irradiation, i.e. $\sim 200 \mathrm{~nm}$. The approach used for the determination of the damage buildup was based on the analysis of the decay of the IL signal as the function of the Ar fluence (see Fig. 3). The analysis was performed for both mono- and polycrystalline samples: results were found to be very similar in both cases. This finding confirms that the luminescence technique is a proper tool for comparative analysis of radiation damage in single- and polycrystals. Fig. 3 also shows that the IL signal is vanishing above $10^{14} \mathrm{~cm}^{-2}$, i.e. quite early when compared with the increase of $f_{D}$ estimated on the basis of RBS/C results.

The mechanisms leading to the fast decay of the IL signal is not yet elucidated. However, it seems that it mostly relies on the formation of non-radiative recombination centers resulting from the creation of vacancies by Ar ion irradiation. Thus, the IL may disappear already at the early stages of irradiation without altering the dechanneling of analyzing ions in RBS/C experiments ( $f_{D}$ parameter) which is mainly sensitive to the concentration of interstitial atoms displaced from their original positions and is almost insensitive to the production of

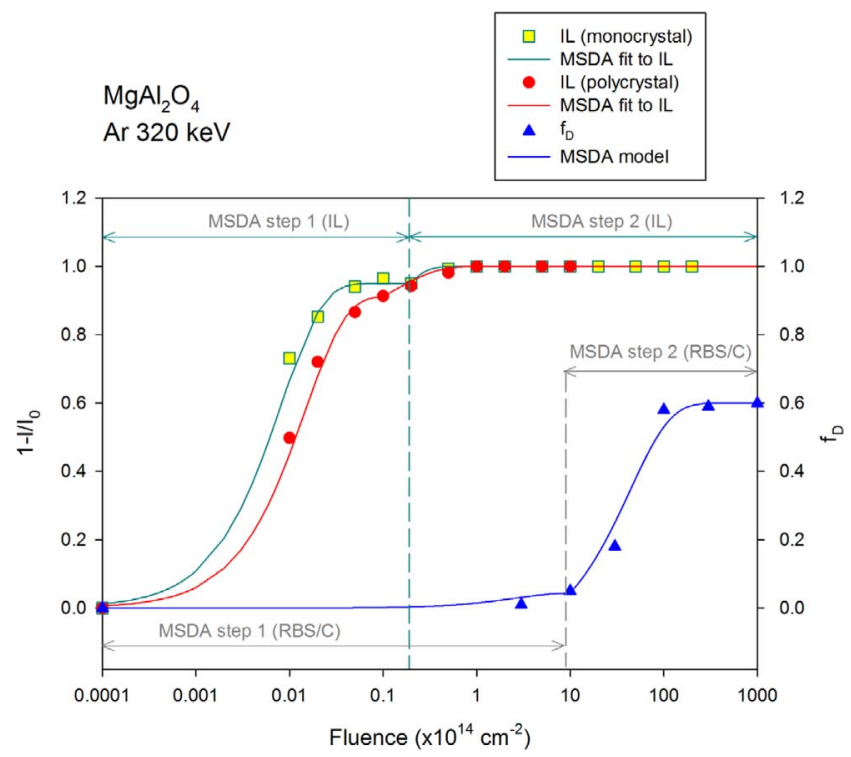

Fig. 3. Damage accumulation kinetics in $\mathrm{MgAl}_{2} \mathrm{O}_{4}$ irradiated with $320 \mathrm{keV} \mathrm{Ar}{ }^{+}$ions calculated from: RBS/C data (triangles) and ionoluminescence data (circles and squares). Lines are fits with the MSDA model assuming a two-step process.

vacancies [11]. Actually, as the increase of $f_{D}$ is related to the transformation of small defect clusters into dislocations or dislocation loops [12], such a transformation is observed at relatively high irradiation fluences. The IL technique thus appears as a complementary tool for the analysis of the damage production at low ion fluences where the RBS/C technique is almost insensitive.

The CL technique may be used together with the IL one, the advantages of CL being a high sensitivity and an ability to work at low electron energies (Ref. [24] and I. Jozwik et al. in these proceedings). An interesting capability of this method is its ability to probe early stages of damage accumulation process, i.e. materials containing low concentration of small defects, when RBS/C method is almost insensitive. The use of luminescence to magnesium aluminate spinel clearly indicated the existence of new defect transformation appearing at very low $\left(\sim 2 \times 10^{13} \mathrm{~cm}^{-2}\right)$ irradiation fluence which cannot be identified by RBS/C. 

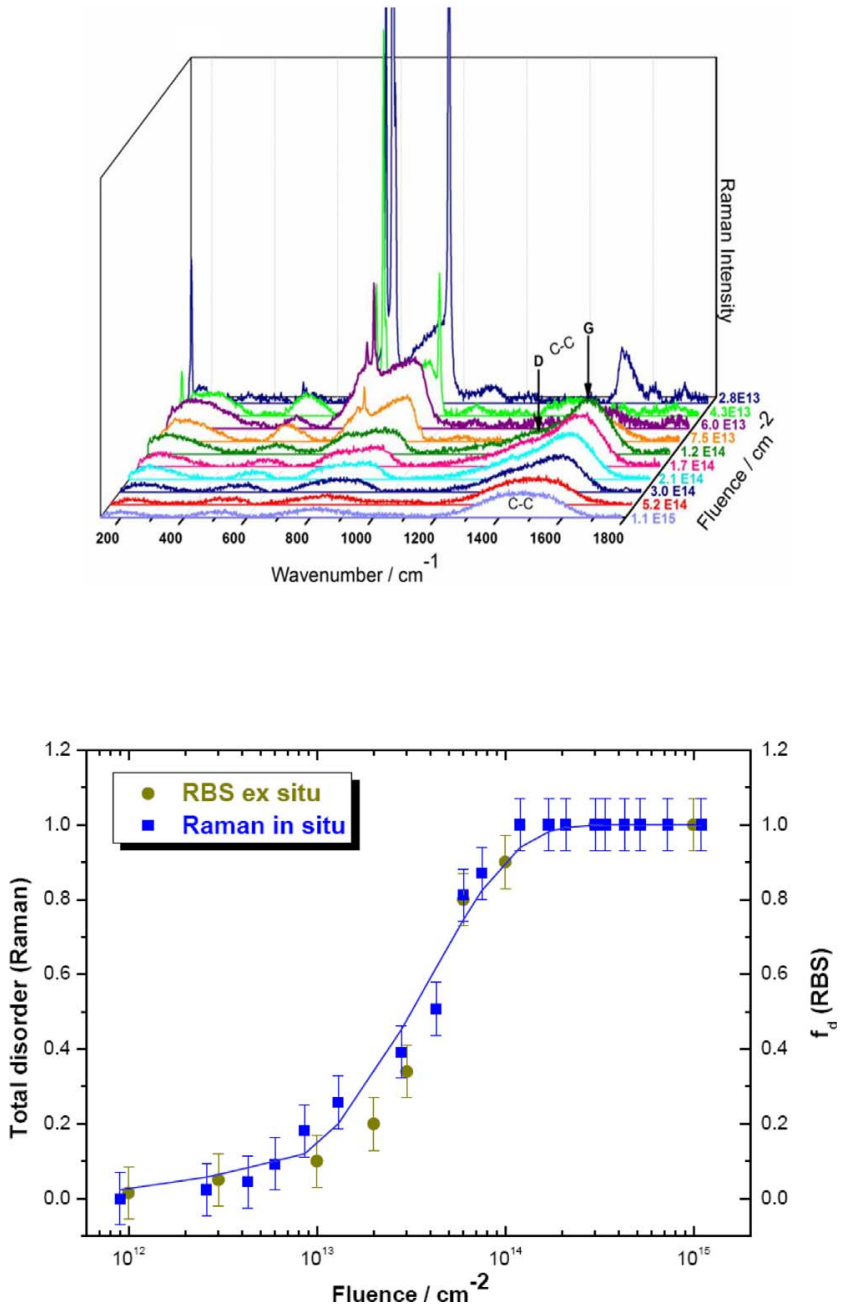

Fig. 4. Raman and RBS/C results obtained on SiC samples irradiated with $900 \mathrm{keV}$ I ions. Evolution of Raman spectra as a function of the I fluence (upper figure), and damage accumulation buildups extracted from both Raman and RBS/C data (lower figure). Lines are fits with the MSDA model assuming a two-step process.
Raman spectroscopy may also be used for the study of damage production in ion-irradiated mono- and polycrystalline materials $[22,24]$. Serious advantages of this technique are: (i) its speed of execution, (ii) the possibility to record data in situ during irradiation, and (iii) the capacity to extract depth distribution profiles. The large number of peaks generally present in Raman spectra, corresponding to various vibrational modes, may constitute excellent probes to sense different atomic configurations. This specificity is shown in Fig. 4 which presents results of Raman and RBS/C experiments performed on ionirradiated $\mathrm{SiC}$ samples (although $\mathrm{SiC}$ is not an oxide, the data recorded on this material provide an illustrative example of the excellent correlation that may occur between Raman and RBS/C results). Fig. 4 (top) show the evolution of Raman spectra recorded in situ during irradiation of a SiC sample with $900 \mathrm{keV}$ I ions [25]. It is quite clear that the shape of Raman spectra presents strong modifications with increasing ion fluences: the main peaks related to the crystalline phase around $1000-1200 \mathrm{~cm}^{-1}$ decrease, whereas the wide bump at $1500 \mathrm{~cm}^{-1}$ due to disorder production increases. The increase of this latter contribution is plotted as a function of the ion fluence in Fig. 4 (bottom) and compared to the increase of the parameter $f_{D}$ measured by RBS/C. This figure shows a perfect agreement between the defect accumulation buildups determined using the two techniques of analysis. However, it is worth mentioning that, in some cases, the relation between changes in Raman spectra and atomic configurations remains difficult to establish.

\section{Recent progress in the understanding of the damage accumulation process}

There is a large amount of issues that are still waiting for being elucidated concerning the description of the damage accumulation in ion-irradiated oxides. Among them, the knowledge of the structure of the defects formed in the early stages of irradiation, where TEM is inefficient, is worthwhile to address. The most likely hypothesis which can be formulated on the basis of $\mathrm{ZnO}$ data [16] and MD simulations of $\mathrm{UO}_{2}[21]$ is that these defects consist of small, basal dislocation loops. The main problem to assess this assumption relies in the fact that TEM samples have a thickness of several tens of nanometers, whereas the size of radiation defects is a few nanometers. Consequently, defects occupy only a small fraction of the examined samples. The recent

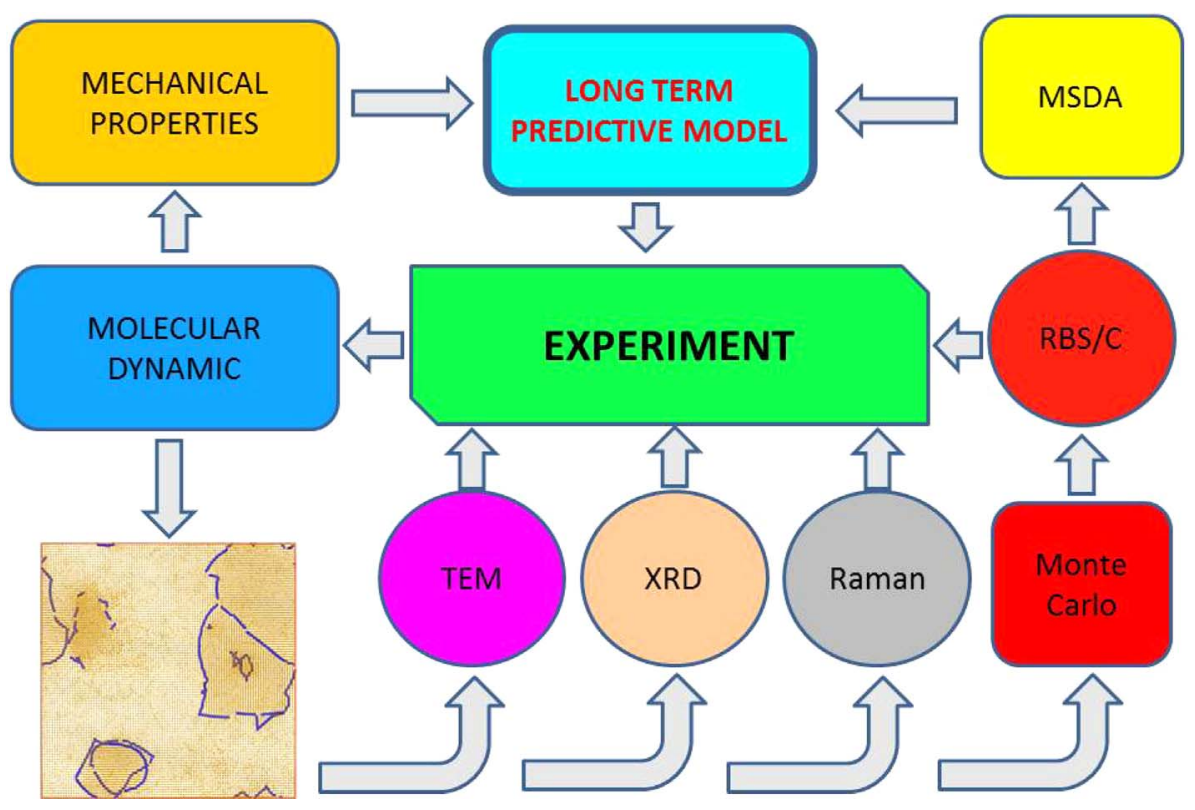

Fig. 5. Schematic representation of a holistic approach for the study of radiation effects in materials. 


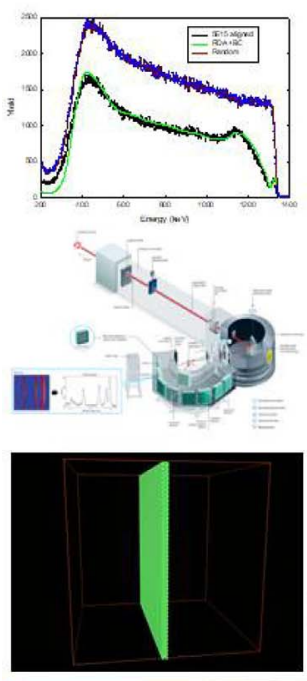

$1 \mathrm{~nm}$
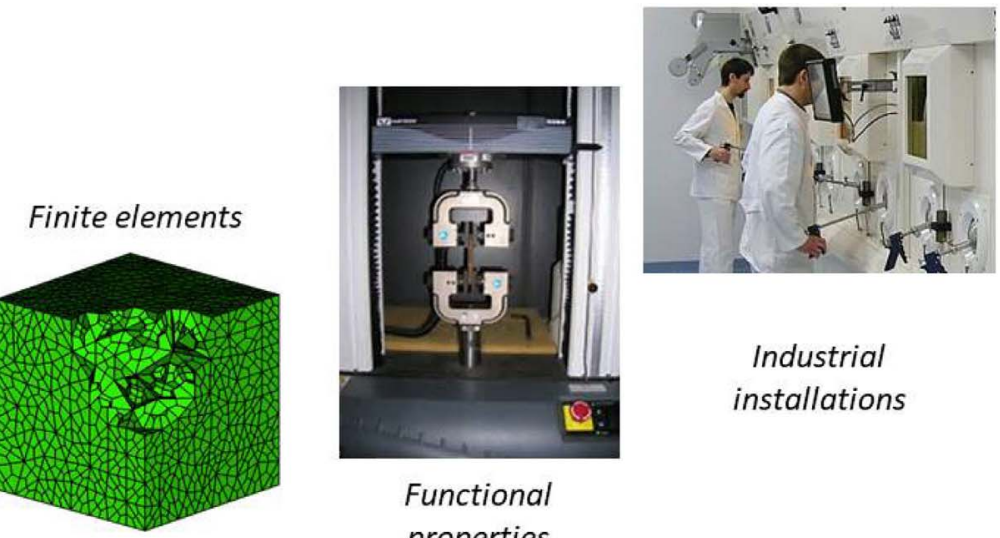

Industrial

installations

Functional

properties

Molecular Dynamics

Structural analysis

$1 \mathrm{~mm}$

$1 \mathrm{~cm}$

$10 \mathrm{~m}$

Fig. 6. Diagram showing the studies that may be performed for the investigation of the properties of irradiated materials at various length scales.

development of sample preparation methodologies, using new, advanced ion etching devices (e.g. Pico-Mill) which make possible the preparation of much thinner TEM lamellas, may constitute a significant step forward in this field.

Another problem that needs to be solved relies on the fact that all available experimental techniques are restricted to the analysis of the post-mortem state of the irradiated sample. Even in recent in situ experiments which consist in a series of irradiation and analysis sequences, samples are analyzed not earlier than seconds after the end of the irradiation process. Since displacement cascades last about $10^{-10} \mathrm{~s}$, all the processes that take place during and soon after the cascade formation are experimentally unobservable. The only approach that may address this issue is the use of computer modeling, via mainly MD and kinetic MC simulations. However, even when computer modeling is used, the following problems remain to be solved: (i) a reliable reproduction of actual experimental conditions in MD simulations, particularly the stress evolution as measured using XRD; (ii) the bridging of the time gap between MD simulations (possible to carry out up to roughly one hundred of picoseconds) and experiments (seconds and more after the ion impacts).

Once a satisfactory agreement is obtained between computer simulation results and the structural properties of irradiated materials, their mechanical properties may be predicted by using constitutive models [26] and/or finite element calculations [27]. The agreement between the predictions of mechanical models and experimental results may then be checked by using the nanoindentation technique (for ionirradiated samples) or mechanical tests carried out in hot cells (for samples irradiated in nuclear reactor) via several rounds of validation.

The final outcome of the work described in this paper (schematically presented in Fig. 5) is thus to build a solid basis for long-term predictive models of material behavior upon irradiation which is highly required for the development of new nuclear technologies.

An interesting aspect of the proposed program is that the studies of radiation damage in oxides cover not only a large time scale (from femtoseconds to years), but also a huge range of dimensions (from nanometers to meters). This aspect is schematically presented in Fig. 6 which also indicates the final goal of studies of irradiated materials in view of future industrial applications.

\section{Summary}

Despite many years of research, the study of the mechanisms of defect accumulation in ion-irradiated oxides remains a challenge for the next generations of scientists. Current issues are mainly related to the design and development of new nuclear reactors that take safety requirements into account. It is therefore necessary to develop models able of predicting the behavior of materials over a long period of time and under extreme conditions: high temperatures, atypical corrosive media, and high irradiation doses.

The optimal solution to try to solve the difficult problem of radiation damage formation in solid seems to be a holistic approach based on a careful validation of computer simulations at various stages of the radiation process: from the simulation of displacement cascades to the prediction of the mechanical properties on real-scale constructions. This issue is far from being resolved, but it undoubtedly constitutes both a fascinating subject of research and a new approach to the development of materials intended to be used in harsh environments.

\section{Acknowledgement}

This study has been partly supported by the COPIN project: a bilateral agreement between French and Polish nuclear laboratories.

\section{References}

[1] W.J. Weber, R.C. Ewing, Scientific basis for nuclear waste management XXV, Mater. Res. Soc. Symp. Proc. 713 (2002) 443.

[2] S.J. Zinkle, C. Kinoshita, J. Nucl. Mater. 251 (1997) 200.

[3] R. Devanathan, Nucl. Instr. Meth. Phys. Res. B 267 (2009) 3017.

[4] Y. Zhang, In-Tae-Bae, W.J. Weber, Nucl. Instr. Meth. Phys. Res. B 266 (2008) 2828.

[5] L. Thomé, A. Debelle, F. Garrido, S. Mylonas, B. Décamps, C. Bachelet, G. Sattonnay, S. Moll, S. Pellegrino, S. Miro, P. Trocellier, Y. Serruys, G. Velisa, C. Grygiel, I. Monnet, M. Toulemonde, P. Simon, J. Jagielski, I. Jozwik-Biala, L. Nowicki, M. Behar, W.J. Weber, Y. Zhang, M. Backman, K. Nordlund, F. Djurabekova, Nucl. Instr. Meth. Phys. Res. B 307 (2013) 43.

[6] L.R. Corrales, Nucl. Instr. Meth. Phys. Res. B 218 (2004) 95.

[7] W.J. Weber, Nucl. Instr. Meth. Phys. Res. B 166-167 (2000) 98.

[8] L. Thomé, S. Moll, A. Debelle, F. Garrido, G. Sattonnay, J. Jagielski, Adv. Mater. Sci. Eng. (2012) Article ID 905474.

[9] S.J. Zinkle, G.S. Was, Acta Mater. 61 (2013) 735.

[10] A. Chartier, L. Van Brutzel, J.-P. Crocombette, Nucl. Instr. Meth. Phys. Res. B 286 (2012) 154.

[11] J.R. Tesmer, M. Nastasi (Eds.), Handbook of Modern Ion Beam Materials Analysis, 
Materials Research Society, Pittsburgh PA, USA, 1995ISBN 1-55899-254-5.

[12] J. Jagielski, L. Thomé, Appl. Phys. A 97 (2009) 147.

[13] S. Pellegrino, J.-P. Crocombette, A. Debelle, T. Jourdan, P. Trocellier, L. Thomé, Acta Mater. 102 (2016) 79.

[14] S. Moll, L. Thomé, G. Sattonnay, A. Debelle, F. Garrido, L. Vincent, J. Jagielski, J. Appl. Phys. 106 (2009) 073509.

[15] F. Garrido, C. Choffel, L. Thomé, J.-C. Dran, L. Nowicki, A. Turos, J. Domagala, Nucl Instr. Meth. Phys. Res. B 136 (1998) 465.

[16] G. Perillat-Merceroz, P. Gergaud, P. Marotel, S. Brochen, P.-H. Jouneau, G. Feuillet, J. Appl. Phys. 109 (2011) 023513.

[17] L. Nowicki, A. Turos, R. Ratajczak, A. Stonert, F. Garrido, Nucl Instr. Meth. Phys Res. B 240 (2005) 277.

[18] P. Jozwik, NCBJ Otwock/Swierk (Ph.D. thesis), (2017).

[19] A. Chartier, C. Onofri, L. Van Brutzel, C. Sabathier, O. Dorosh, J. Jagielski, Appl. Phys. Lett. 109 (18) (2016) 81902.

[20] K. Yasunaga, K. Yasuda, S. Matsumura, T. Sonoda, Nucl. Instr. Meth. B 266 (2008) 287.
[21] K. Yasuda, C. Kinoshita, S. Matsumura, A.I. Ryazanov, J. Nucl. Mater. 319 (2003) 74.

[22] I. Jozwik, J. Jagielski, G. Gawlik, P. Jozwik, R. Ratajczak, G. Panczer, N. Moncoffre, A. Wajler, Phys. Chem. Miner. 43 (2016) 439

[23] G. Guimbretiere, L. Desgranges, C. Jegou, A. Canizares, P. Simon, R. Caraballo, N. Raimboux, M.-F. Barthe, M.R. Ammar, O.A. Maslova, F. Duval, R. Omnee, IEEE Trans. Nucl. Sci. 61 (2014) 2045.

[24] J. Jagielski, G. Gawlik, I. Jozwik-Biala, G. Panczer, N. Moncoffre, X. Wang, R. Ratajczak, M. Swirkowicz, L. Thomé, Nucl. Instr. Meth. Phys. Res. B 332 (2014) $60-62$.

[25] S. Miro, E. Bordas, L. Thomé, J.-M. Costantini, F. Leprêtre, P. Trocellier, Y. Serruys, L. Beck, D. Gosset, R. Verlet, J. Huguet-Garcia, M. Tupin, M. Belleil, J. Raman Spectrosc. 47 (2016) 476.

[26] N.S. Ottosen, M. Ristinmaa, The Mechanics of Constitutive Modeling, Elsevier, ISBN: 978-0-08-044606-6.

[27] J.N. Reddy, An Introduction to the Finite Element Method, McGraw-Hill, ISBN: 9780071267618 . 